\title{
Medical Image of the Week: Pulmonary Alveolar Proteinosis
}

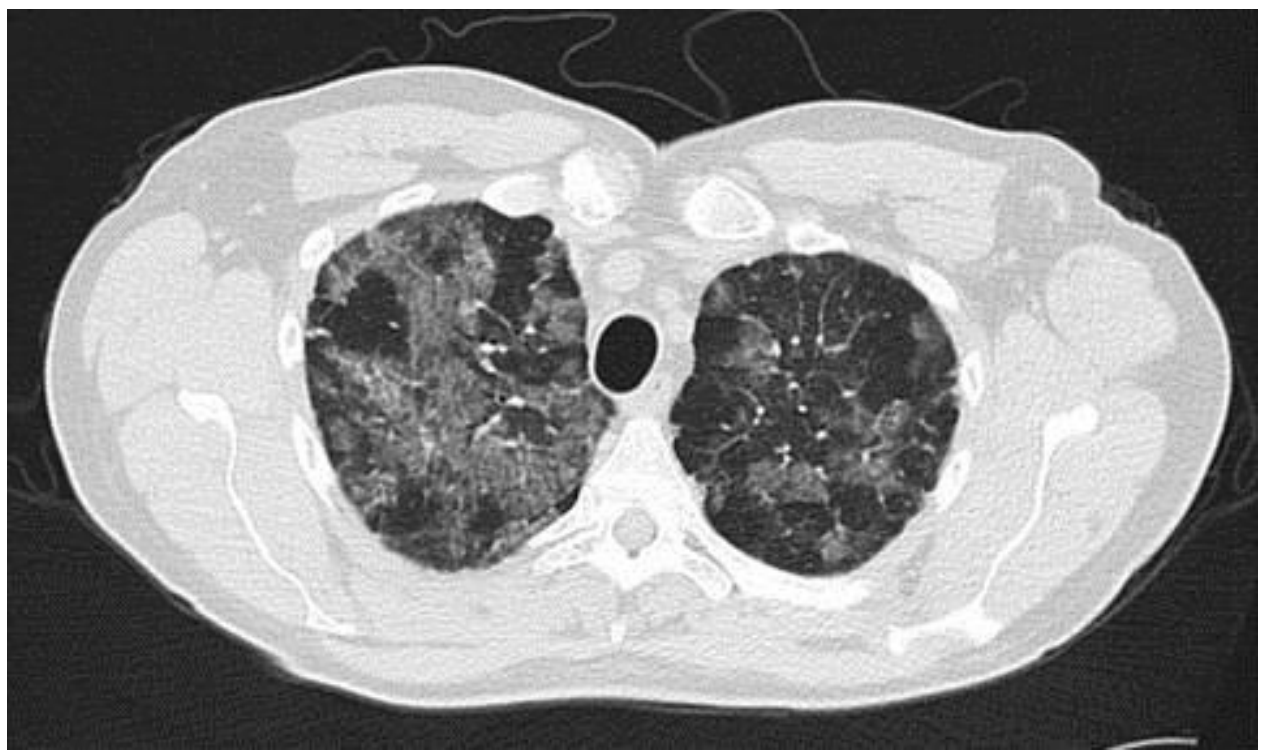

Figure 1. Representative image from an axial CT scan showing "crazy paving".

Pulmonary alveolar proteinosis (PAP) is a rare pulmonary disease characterized by alveolar accumulation of surfactant (1). It usually results from mutations in surfactant proteins or granulocyte macrophage-colony stimulating factor (GM-CSF) receptor genes. Other causes include toxic inhalation or hematological disorders, or it may be auto-immune, with anti-GM-CSF antibodies blocking activation of alveolar macrophages.

Auto-immune alveolar proteinosis is the most frequent form of PAP, representing $90 \%$ of cases. Although not specific, high-resolution computed tomography shows a characteristic diffuse ground-glass attenuation with superimposed interlobular septal thickening and intralobular lines which is called "crazy paving" (Figure 1). In most cases, bronchoalveolar lavage findings establish the diagnosis. Whole lung lavage is the most effective therapy, especially for auto-immune disease. Novel therapies targeting alveolar macrophages (recombinant GM-CSF therapy) or anti-GM-CSF antibodies (rituximab and plasmapheresis) are considered investigational.

Bhupinder Natt MD FACP

Division of Pulmonary, Allergy, Critical Care and Sleep

Banner University Medical Center, Tucson (AZ) USA

\section{Reference}

1. Borie R, Danel C, Debray MP, Taille C, Dombret MC, Aubier M, Epaud R, Crestani B. Pulmonary alveolar proteinosis. Eur Respir Rev. 2011 Jun;20(120):98-107. [CrossRef] [PubMed] 